\title{
Editorial: Urban Ecosystem Services and Disservices in Tropical Regions
}

\author{
Franco L. Souza ${ }^{1 * t}$, Jose A. Puppim de Oliveira ${ }^{2+}$ and Christopher A. Lepczyk ${ }^{3 \dagger}$ \\ ${ }^{1}$ Federal University of Mato Grosso do Sul, Campo Grande, Brazil, ${ }^{2}$ Fundação Getúlio Vargas (FGV-EAESP and FGV \\ EBAPE), São Paulo, Brazil, ${ }^{3}$ School of Forestry and Wildlife Sciences, Auburn University, Auburn, AL, United States
}

Keywords: biodiversity-ecosystem function, cultural service, heat island, frugivory network, ecosystem disservice

\section{Editorial on the Research Topic}

\section{Urban Ecosystem Services and Disservices in Tropical Regions}

The tropics (Figure 1A) contain most of world's biodiversity (Barlow et al., 2018), providing a living laboratory of ecological and evolutionary processes, and presenting an immense potential for tapping this rich biodiversity for local and global benefits. While the typical image of the tropics is a green and clean location, this often does not hold true as many places are intrinsically urban, such as the Brazilian Amazon. In fact, the tropics currently house $\sim 40 \%$ of the world's population and expected to increase to $50 \%$ by 2050 (State of the Tropics, 2020). As the population continues to grow, many cities and peri-urban areas in the tropics are undergoing rapid habitat loss, resulting in the loss of unique ecosystems and species (McDonald et al., 2018). These losses affect a variety ecosystem services, such as seed dispersal and pollination, disaster protection, water and flood protection, microclimate regulation, pollution reduction and cultural identity. Not only are ecosystem services being lost, but the growing consumption that an urbanized global society imposes on tropical ecosystems is causing the emergence of ecosystem disservices including zoonotic diseases, increase of urban heat islands effects and people disconnection with nature and consequent human well-being. Furthermore, urban biodiversity can itself generate ecosystem disservices that may cause effects perceived as harmful, unpleasant, or unwanted (Shackleton et al., 2016). These disservices can also be amplified by climate change, which could augment the risks of disease burdens in tropical cities (Reiner et al., 2015). As a result, increasing urban biodiversity with the goal of changing ecosystem services can be challenging due to the necessity to manage associated ecosystem disservices (Blanco et al., 2019).

Aside from the changing nature of ecosystem services, tropical cities also face significant deficiencies in urban infrastructure, such as sanitation and waste management facilities (Paes et al., 2021). On top of infrastructure problems, many residents of tropical cities are poor and face daily challenges ranging from their geopolitical outlook through their vulnerabilities associated to synergic effects from climate change including pollution and diseases (Reiner et al., 2015; Soergel et al., 2021). Thus, a major challenge facing tropical cities is how to reconcile the conflicts between human well-being and biodiversity in terms of ecosystem services and disservices. This challenge is more pronounced in tropical cities than temperate cities due to the lack of studies and the varying approaches used, which makes comparisons related to ecosystem services across cities difficult for identifying factors that can inform conservation and management (Nagendra et al., 2018; Rutebuka et al., 2019). To begin addressing the gaps in knowledge related to ecosystem services and disservices in tropical cities are four articles that describe novel findings as part of this special issue (Figure 1B).

In the first study, Teodosio-Faustino et al. demonstrate that the structure of the frugivore network in urban parks can be a random process, emphasizing the importance in understanding 


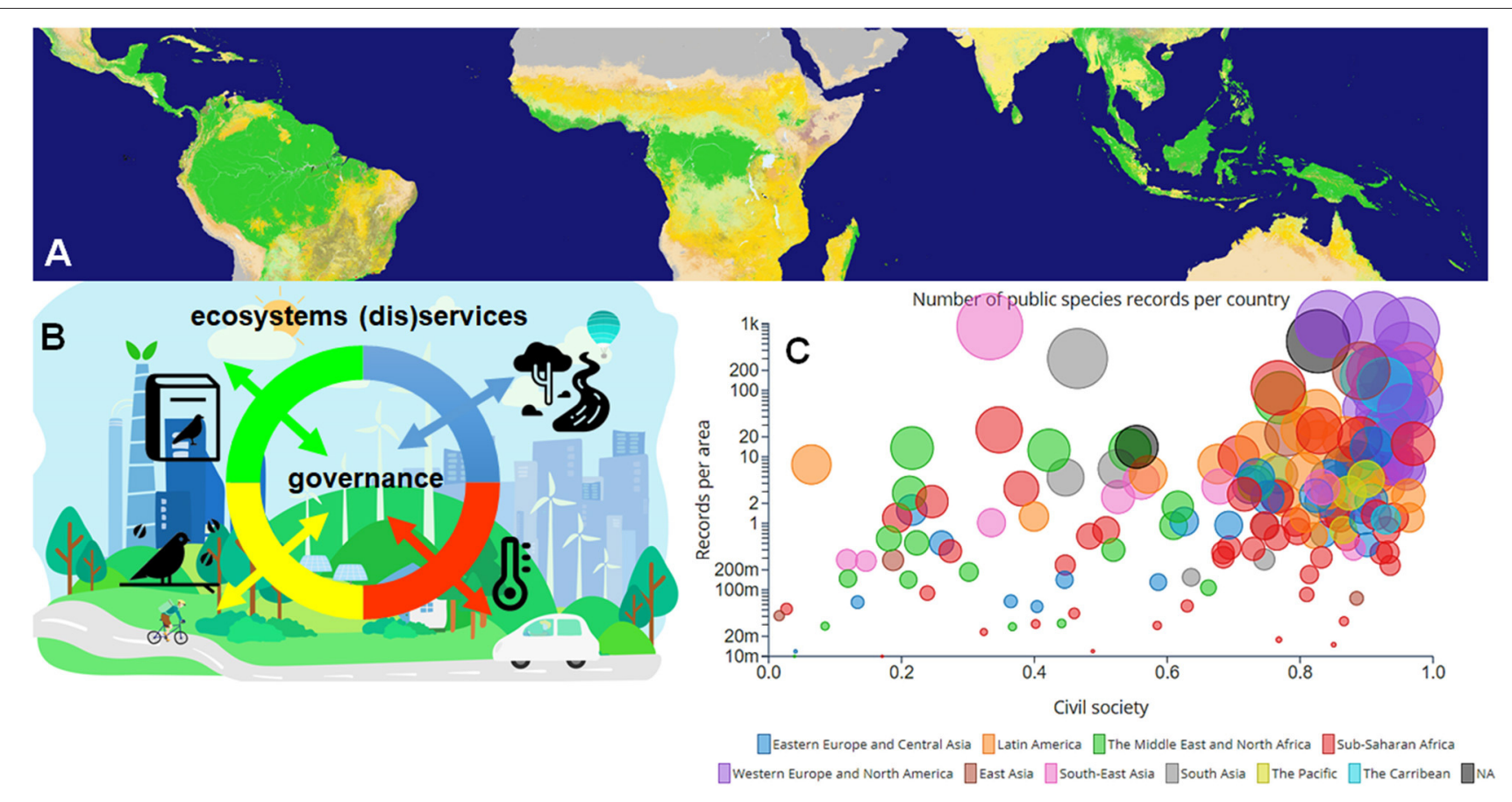

FIGURE 1 | The tropical region of the world $(\mathbf{A})$ are expected to harbor most of human population in the next decades. The urbanization process (B) is a driver in the tropics that can compromise ecosystem services (e.g., frugivory networks, ecosystem functions in urbanized streams) as well as the emergence of ecosystem disservices (e.g., urban heat islands, loss of cultural diversity), all of them addressed in this Research Topic, that must be recognized and managed by distinct governance scale. Countries from this region exhibit distinct political, socioeconomic differences and colonial history that will reflect in the ways civil society organizations (here, a proxy for governance) identify the importance of biodiversity (here, a proxy for ecosystem services and disservices) for human-wellbeing (C). Civil society is related to freedom of association. The variable captures if civil society organizations can operate freely and without fear of repression from the government, and whether new or oppositional political parties are free to take form and participate in elections. This Research Topic Urban Ecosystem Services and Disservices in Tropical Regions advances in some of these challenges and emphasize the importance for continuing pursuit of new ideas and goals. Map in (A) modified from https://earthobservatory.nasa.gov/; urban figure in (B) from https://www.freepik.com/; icons from https://thenounproject.com/; (C) is a time window from 2000, approximately the year where ecosystem services approaches were made explicit in literature and was generated by the Bio-Dem

(www.bio-dem.surge.sh), an open-source software to explore the relationship between the availability of species occurrence records and the political framework in countries worldwide and through time. Civil society variable in x-axis ranges from 0 to 1, where higher scores indicate higher levels of associational freedom. Civil society organizations may push governments to better manage biodiversity, provide infrastructure to collect biodiversity data or by collecting it themselves. Public species records are records from public platform such as GBIF.

the role of disturbance in the organization of ecological networks in solving theoretical approaches, such as neutral- and niche-based processes governing ecosystem services in tropical urban areas. Following on this first study is an analysis by Zúñiga-Sarango et al. who demonstrate that urbanization affects aquatic keystone species and ecosystem functioning relationships in Andean streams via nutrient enrichment and substrate homogenization causing the loss of taxonomic and functional diversity in shredders and organic matter breakdown decline, suggesting that losing ecosystem functions can compromise several ecosystem services.

Climate change also brings significant challenges for tropical cities. Temperature changes across $250+$ tropical cities from 1960 to 2020 suggests that there will be significant impacts in urban heat island therefore, urban and regional decision-makers should consider the use of ecosystem and green infrastructure options to regulate local temperature and provide thermal comfort by transpirative cooling and shading (Marcotullio et al.). Finally, the impacts of ecosystem losses go beyond the direct urban services.
Valente-Neto et al. verified that the negative relationship between urban impervious surface and bird cultural richness may indicate that people living in more urbanized areas experience nature less compared to people in less urbanized areas, which can affect their psychological well-being. In highly urbanized areas, contact with culturally valued birds and cultural services provided by birds may also diminish while the negative relationship between functional richness and urbanization also indicate that highly urbanized areas may be losing important ecosystems services provided by birds (see also Echeverri et al., 2021).

While the articles of this special issue help to advance our socio-ecosystem knowledge of tropical cities, we still lack basic data about many of them. Despite the evident importance of urban ecosystem services as drivers of opportunities for conservation, governance, biodiversity management, and human well-being, many challenges persist in tropical regions. For example, if biodiversity is considered a proxy for ecosystem service and disservice and civil society engagement a proxy for governance then, from a historical perspective, countries 
with more robust civil society organizations are apparently less willing to compromise ecosystem services. This, in turn, could encourage the mobilization of ecological political actions to hold governments to account for not addressing environmental management adequately (Zizka et al., 2021). Such a relationship is clear for some countries from tropical regions (Figure 1C).

Compared to the northern hemisphere, cities in the southern hemisphere (particularly in tropical regions) exhibit significantly lower prosperity, infrastructure, development, quality of life, and environmental sustainability (State of the Tropics, 2020), most of them related to several UN Sustainable Development Goals such as clean water and sanitation, affordable and clean energy, sustainable cities and communities, and climate action. Even within a same geographical region, many disparities at a local scale are still challenges for the transfer of knowledge between one country and another. Some of these challenges, and their potential resolution, are considered in this Research Topic, but

\section{REFERENCES}

Barlow, J., França, F., Gardner, T. A., Hicks, C. C., Lennox, G. D., et al. (2018). The future of hyperdiverse tropical ecosystems. Nature 559, 517-526. doi: 10.1038/s41586-018-0301-1

Blanco, J., Dendoncker, N., Barnaud, C., and Sirami, C. (2019). Ecosystem disservices matter: towards their systematic integration within ecosystem service research and policy. Ecosyst. Serv. 36:100913. doi: 10.1016/j.ecoser.2019.100913

Echeverri, A., Karp, D. S., Frishkoff, L. O., Krishnan, J., Naidoo, R., Zhao, J., et al. (2021). Avian cultural services peak in tropical wet forests. Conserv. Lett. 14:e12763. doi: 10.1111/conl.12763

McDonald, R. I., Colbert, M., Hamann, M., Simkin, R. and Walsh, B. (eds.). (2018). Nature in the Urban Century: A Global Assessment of Where and How to Conserve Nature for Biodiversity and Human Wellbeing. Arlington, VA: The Nature Conservation. Available online at: www.nature.org/content/dam/tnc/ nature/en/documents/TNC_NatureintheUrbanCentury_FullReport.pdf

Nagendra, H., Bai, X., Brondizio, E. S., and Lwasa, S. (2018). The urban south and the predicament of global sustainability. Nat. Sustain. 1, 341-349. doi: 10.1038/s41893-018-0101-5

Paes, M. X., Campos-Silva, J. V., and de Oliveira, J. A. P. (2021). Integrating circular economy in urban Amazon. NPJ Urban Sustain. 1, 1-6. doi: 10.1038/s42949-021-00031-z

Reiner, R. C. Jr., Smith, D. L., and Gething, P. W. (2015). Climate change, urbanization and disease: summer in the city. Trans. R. Soc. Trop. Med. Hyg. 109, 171-172. doi: 10.1093/trstmh/tru194

Rutebuka, E., Olorunnisola, A. O., Taiwo, O. J., Mwaru, F., Asamoah, E. F., and Rukundo, E. (2019). Quantitative review of ecosystem services and disservices studies in the Tropics. Open J. Ecol. 9, 85-106. doi: 10.4236/oje.2019. 94008

Shackleton, C. M., Ruwanza, S., Sanni, G. K. S., Bennett, S., De Lacy, P., Modipa, R., et al. (2016). Unpacking Pandora's Box: understanding and categorizing perhaps more importantly, it highlights the crucial importance of ongoing investigation of these challenges, and evaluating new ideas and goals for their resolution.

\section{AUTHOR CONTRIBUTIONS}

FS: conceptualization and writing-original draft, review and editing. JP and CL: writing-original draft, review and editing.

\section{ACKNOWLEDGMENTS}

FS acknowledges $\mathrm{CNPq}$ that has continuously supported the researches with productivity grant (301306/2018-4). JP acknowledges the support of FAPESP (Grant Nos. 2017/504259 and 2017/003519), CAPES (Grant No. 88881.310380/2018-01), and CNPq (Grant No. 442472/2020).

ecosystem disservices for environmental management and human wellbeing. Ecosystems 19, 587-600. doi: 10.1007/s10021-015-9952-Z

Soergel, B., Kriegler, E., Bodirsky, B. L., Bauer, N., Leimbach, M., and Popp, A. (2021). Combining ambitious climate policies with efforts to eradicate poverty. Nat. Commun. 12:2342. doi: 10.1038/s41467-021-22315-9

State of the Tropics (2020). State of the Tropics 2020 Report. Townsville, QLD: James Cook University.

Zizka, A., Rydén, O., Edler, D., Klein, J., Perrigo, A., Silvestro, D., et al. (2021). Bio-Dem, a tool to explore the relationship between biodiversity data availability and socio-political conditions in time and space. J. Biogeogr. 2021, 1-12. doi: 10.1111/jbi.1 4256

Conflict of Interest: The authors declare that the research was conducted in the absence of any commercial or financial relationships that could be construed as a potential conflict of interest.

Publisher's Note: All claims expressed in this article are solely those of the authors and do not necessarily represent those of their affiliated organizations, or those of the publisher, the editors and the reviewers. Any product that may be evaluated in this article, or claim that may be made by its manufacturer, is not guaranteed or endorsed by the publisher.

Copyright (c) 2021 Souza, Puppim de Oliveira and Lepczyk. This is an open-access article distributed under the terms of the Creative Commons Attribution License (CC $B Y)$. The use, distribution or reproduction in other forums is permitted, provided the original author(s) and the copyright owner(s) are credited and that the original publication in this journal is cited, in accordance with accepted academic practice. No use, distribution or reproduction is permitted which does not comply with these terms. 